\title{
Electrochemical Techniques for Evaluation of Expired Megavit Drugs as Corrosion Inhibitor for Steel in Hydrochloric Acid
}

\author{
Reda S. Abdel Hameed ${ }^{1,2}$, Meshari M. Aljohani ${ }^{3}$, Ayham Bani Essa ${ }^{1}$, Azaa Khaled ${ }^{1}$, \\ Amr. M. Nassar ${ }^{2}$, Magd M. Badr ${ }^{6}$, Saedah R. Al-Mhyawi ${ }^{7}$,Mahmoud S. Soliman ${ }^{4,5}$ \\ ${ }^{1}$ Basic Science Department, Preparatory Year, University of Ha'il, 1560, Hail, KSA. \\ ${ }^{2}$ Chemistry Department, Faculty of Science, Al- Azhar University,11884, Cairo, Egypt. \\ ${ }^{3}$ Department of Chemistry, Faculty of Science, University of Tabuk, Tabuk 71491, KSA. \\ ${ }^{4}$ Department of Pharmaceutics, Faculty of pharmacy, Al- Azhar University,11884, Cairo, Egypt. \\ ${ }^{5}$ Department of Pharmaceutics, Faculty of pharmacy, University of Ha'il, 1560, Hail, KSA. \\ ${ }^{6}$ Petrochemical Department, Egyptian Petroleum Research Institute, Cairo, Egypt. \\ ${ }^{7}$ Chemistry department, Faculty of Science, University of Jeddah, Jeddah, KSA. \\ *E-mail: mredars2@yahoo.com
}

doi: $10.20964 / 2021.04 .15$

Received: 6 December 2020 / Accepted: 22 January 2021 / Published: 28 February 2021

\begin{abstract}
Megavit zinc drugs is a physical and mental activity enhancer it is so dangerous to be left in the environment after its expired as it is harmful to the child's, so the present work introduces an idea for using it in the expired medicinal form as potential nontoxic inhibitor for steel corrosion against acidic $1.0 \mathrm{M} \mathrm{HCl}$. The electrochemical techniques were applied in the evaluation of inhibition efficiency of megavit drugs in the expired form. Effect of expired drug concentration and reaction temperature were studied. The corrosion inhibition was found to increase by increasing concentration and decreased with rising the temperature. Potentiodynamic polarization data show that the expired drugs retard both anodic and cathodic potential meaning it is a mixed inhibitor. The electrochemical impedance spectroscopy EIS, techniques data shows that the expired drug help to increases the polarization resistance by adsorbing on metal/electrolyte interface. This kind of adsorption found to obeying Langmuir adsorption isotherm model. The data obtained from the used electrochemical techniques exhibit good agreement between them with $( \pm 2)$ to prove that the used expired megavit zinc medicinal drugs act as green corrosion inhibitor for the c-steel in $1.0 \mathrm{M} \mathrm{HCl}$ acidic environment and in an industrial field.
\end{abstract}

Keywords: Electrochemical techniques; EIS; Potentiodynamic Polarization, Green inhibitors, Expired drugs; Megavit zinc drugs.

\section{FULL TEXT}


(C) 2021 The Authors. Published by ESG (www.electrochemsci.org). This article is an open access article distributed under the terms and conditions of the Creative Commons Attribution license (http://creativecommons.org/licenses/by/4.0/). 